\title{
Effectiveness in Dynamic Balance: a Comparison between Foot Muscle Strengthening Using Elastic Band and without Elastic Band in Children Aged 8-12 with Flexible Flatfeet
}

\author{
Indri Listyorini, Marietta Shanti, Tertianto Prabowo \\ Department of Physical Medicine and Rehabilitation, Faculty of Medicine, Universitas Padjajaran- \\ Dr. Hasan Sadikin General Hospital
}

\begin{abstract}
Objective: To compare the effects of foot muscle strengthening exercises with and without elastic band to the dynamic balance function in children aged 8-12 years with flexible flatfeet.

Methods: Forty-one children (aged 8-12 years) with flexible flatfeet and dynamic balance problem were randomly allocated into either the intervention or control group. Both groups received thrice weekly training for 6 weeks. The foot strengthening exercise regimens consisted of pronation, supination, short foot, and tiptoeing using elastic band for the intervention group and without elastic band for the control group. Star Excursion Balance Test (SEBT) was tested before and after 6 weeks of training.
\end{abstract}

Results: A statistically significant difference of normalized SEBT scores was found for both groups in both legs $(\mathrm{p}=0.00, \mathrm{p}<0.05)$. The intervention group was significantly better than the control group for both right and left legs $(\mathrm{p}=0.00, \mathrm{p}<0.05)$.

Received:

November 21, 2014

Revised:

February 6, 2015

Accepted:

February 9, 2015
Conclusions: Foot muscle strengthening either with or without elastic band improves dynamic balance in children aged 8-12 years with flexible flatfeet. Exercise given with elastic band significantly shows better improvement in the dynamic balance compared to without elastic band.

Keywords: Flexible flatfeet, strengthening exercises, elastic band, dynamic balance, star excursion balance test

IJIHS. 2015;3(1):26-32

\section{Introduction}

Flatfeet is a condition where the foot has a flatter medial longitudinal arch. This condition can be classified into flexible and rigid types. Flatfeet is the most common musculoskeletal problem found in children, where the majority have the flexible type. ${ }^{1}$

Symptoms such as limb pain, easily fatigued, balance problem, and gait pattern disorder are mostly associated with flatfeet. These symptoms are due to abnormality of subtalar pronation during propulsion. ${ }^{1}$ A study in India found significant differences in balance

\footnotetext{
Correspondence:

Indri Listyorini, Department of Physical Medicine and Rehabilitation, Faculty of Medicine, Universitas Padjadjaran-Dr. Hasan Sadikin General Hospital Jl. Pasteur No. 38, Bandung, Indonesia

e-mail: indrilistyorini@gmail.com
}

of individual with normal feet compared to those with flexible flatfeet. ${ }^{2}$ Dynamic balance is essential in most activities. It is expected that children participate in more dynamic activities than adults. ${ }^{3}$

The extrinsic foot muscle strengthening exercise is an exercise that is usually aimed to help stabilizing the midtarsal joint and medial longitudinal arch during stance phase. ${ }^{4}$ Meanwhile, the intrinsic muscle strengthening is intended to control the foot pronation. ${ }^{5} \mathrm{~A}$ study in India has investigated feet muscles strengthening exercise effectiveness among 10-12 year-old children. ${ }^{3}$ Exercises were given through activities such as foot transferring tea cup and tip toeing, which were targetted to increase movement accuracy and feet muscle strength. The study was performed to evaluate the dynamic balance improvement among subjects with flexible flatfeet. Only female 
subjects were included in this previous study. Specific exercise training with elastic band application has several advantages because it can objectively measure resistance, it is light weighted and also affordable. ${ }^{6}$ A previous study in London has demonstrated increased gastrocnemius muscle volume in children with cerebral palsy after ten weeks of strengthening exercise using the elastic band. ${ }^{7}$

The aim of this study was to compare the effectiveness of foot muscle strengthening exercise using elastic band and without elastic band to improve the dynamic balance in 8-12 year-old children with flexible flatfeet.

\section{Methods}

Fourty one subjects, which included 23 males and 18 females aged 8-12 years old, were recruited from a primary school in West Bandung District during the period of January-March 2014. The inclusion criteria were the followings: (1) Flexible flatfeet (according to Chippaux Smirak Index (CSI) and Jack's test),, 8 (2) dynamic balance disorder (according to Star Excursion Balance Test (SEBT) measurement), ${ }^{10}$ and (3) normal body mass index. Subjects were excluded if there were (1) foot/ankle trauma within the last 6 months, (2) receiving balance training or feet muscle strengthening within the last 3 months, (3) visual and vestibular disturbance, (4) history of head injury within the last 3 months, (5) weakness of lower extremities (manual muscle testing $<5)^{11}$ and $(6)$ has musculoskeletal disfigurement other than the flatfeet. Drop out criteria were incapability to follow SEBT instruction or absent during either pre- or post-intervention measurement or failure to attend training 3 times in a row (20\% of training frequency).

The children volunteered to participate were given a consent form to be signed by the parents. This study has been approved by the ethical committee of Dr. Hasan Sadikin General Hospital to be conducted in allocated subjects. Subjects were simple randomized into either intervention or control groups by blinded physical therapist.

The foot muscle strength of each subject's was measured using manual muscle testing. Measurement was done by an experienced physical therapist who was blinded from preto-post test and to the interventions in order to maximize this study reliability. Each subject would undergo the SEBT measurement twice (pre- and post-intervention) conducted by researchers who were blinded to subject's allocated group.

Supervised training by a physical therapist was given at school. Exercise was contemplated into feet movement training using an elastic band with overload principle. ${ }^{6}$ Feet movement program was provided in the same fashion in both groups, with no elastic band use in the control group. Movements included pronation-supination in sitting position with extended knees, feet shortening, and tip-toeing in one-leg standing position while holding to a static bar. Training was conducted in 3 sessions a week for 6 weeks,

Table 1 Subject Characteristics

\begin{tabular}{lccc}
\hline \multirow{2}{*}{ Characteristics } & \multicolumn{2}{c}{ Group } & \multirow{2}{*}{ p Value } \\
\cline { 2 - 3 } Age (yrs.) & Control (n=20) & Intervention (n=21) & \\
8 & 8 & 5 & \\
9 & 5 & 8 & \\
10 & 4 & 3 & \\
11 & 2 & 3 & \\
12 & 1 & 2 & \\
Median & 9 & 9 & \\
Gender & & & \\
Male & 10 & 13 & $\mathrm{p}=0.83$ \\
Female & 10 & 8 & \\
\hline
\end{tabular}




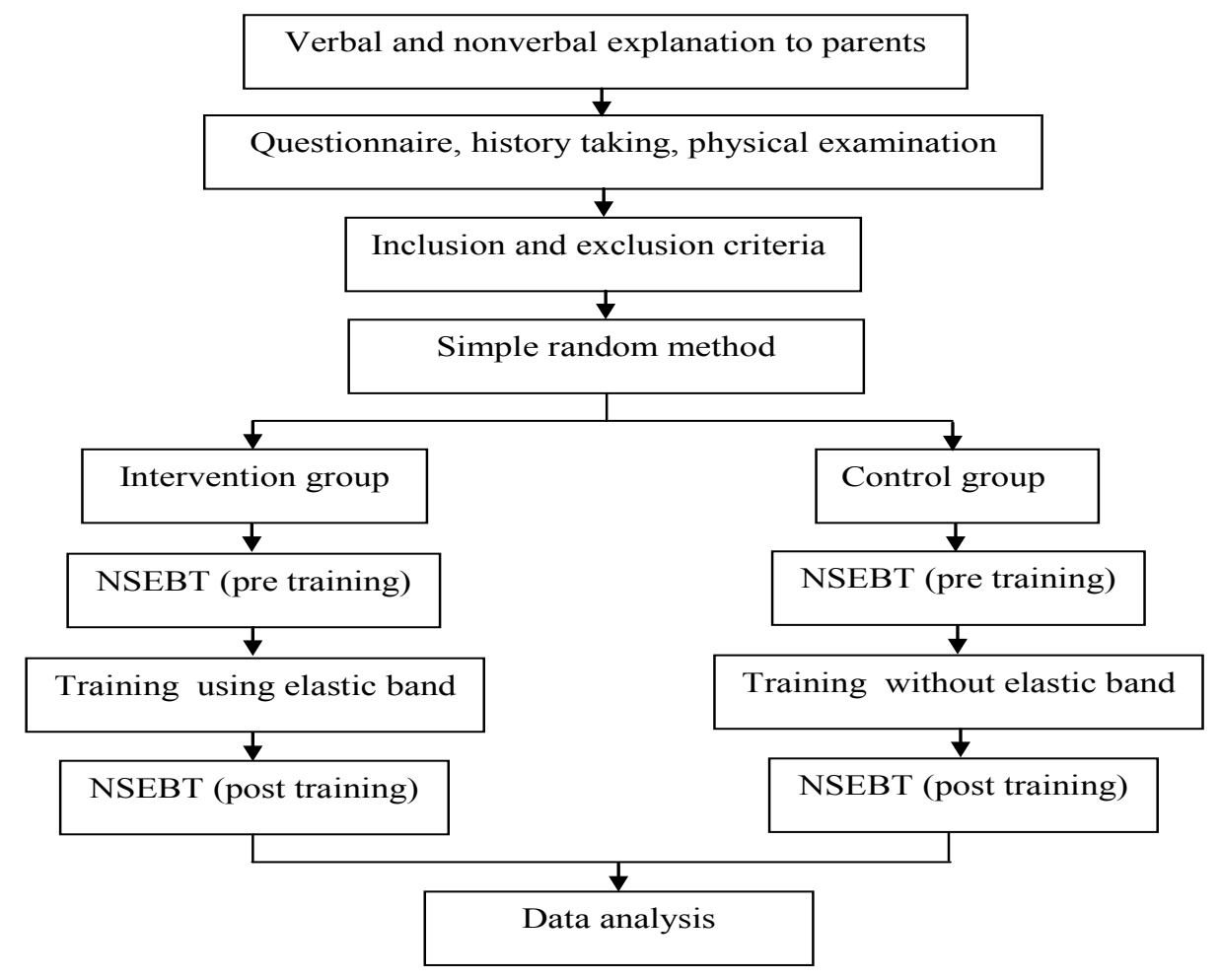

Fig. 1 Study Pattern

with each session consisted of 3 sets of 10-12 repetitions. Exercise was recorded in log book to receive subject's compliance.

The data were analyzed for normality by using the Shapiro Wilk test and the analysis was continued with parametric paired t-test or non parametric Wilcoxon match pair to compare pre- and post-training scores. The independent t-test or Mann Whitney $U$ test was then used to compare the intervention and control group. The whole analysis process was performed using Stat software and a p value of $<0.05$ was considered statistically significant.

\section{Results}

Subjects characteristics were presented above (Table 1). Age median was 9 years old with $\mathrm{p}=0.56$ which means there was no difference between control and intervention groups and was accepted for comparison. In addition, significancy was also shown in male dominance and right foot dominance $(\mathrm{p}>0.05)$ which also means both groups were comparable.
Mean of the right limb length was higher in males than in females $(68.94 \mathrm{~cm})$. However, the differences were not significant $(p=0.64)$ (Table 2). This finding was the same for the left limb length with no significant difference between the two genders $(p=0.59)$. Correlation between age and limb length was analyzed using Kruskal Wallis test (Table 2) and the result was significant. The analysis were then conducted using the percentage of step length to limb length.

Comparison of Normalized Star Excursion Balance Test (NSEBT) score pre- and postintervention in each group showed a higher mean score in post-intervention (Table 3).

A significant increase in post-intervention NSEBT scores was seen in all directions for the intervention group, with a score that was better than the control group for both limbs (Table 4).

\section{Discussion}

This study involved 41 children with flexible 
flatfeet and dynamic balance problem (20 children in control group and 21 children in the intervention group). One child in control group dropped out due to failure to attend training 3 times.

Table 2 Subject Characteristics by Limb Length

\begin{tabular}{lcc}
\hline \multirow{2}{*}{ Characteristics } & \multicolumn{2}{c}{ Mean of Limb Length } \\
\cline { 2 - 3 } & Right & Left \\
\hline Gender & & \\
Male (n=23) & 68.08 & 68.00 \\
Female (n=18) & 68.94 & 68.97 \\
& $\mathrm{t}=-0.47$ & $\mathrm{t}=-0.54$ \\
& $\mathrm{p}=0.64$ & $\mathrm{p}=0.59$
\end{tabular}

Age

Intervention group (yrs.)

\begin{tabular}{lcc}
8 & 62.90 & 62.90 \\
9 & 67.63 & 67.63 \\
10 & 72.33 & 72.50 \\
11 & 74 & 73.67 \\
12 & 71 & 71 \\
& $\mathrm{p}=0.01^{*}$ & $\mathrm{p}=0.01^{*}$ \\
Control group & & \\
(yrs.) & & \\
8 & 63.37 & 63.50 \\
9 & 67.25 & 67 \\
10 & 72 & 71.87 \\
11 & 72.75 & 72.50 \\
12 & 76 & 76 \\
& $\mathrm{p}=0.00^{*}$ & $\mathrm{p}=0.00^{*}$ \\
\hline
\end{tabular}

Note: ${ }^{*}=\mathrm{p}<0.05=$ significant; ${ }^{*}$ Kruskal Wallis test

A previous study demonstrated a significant difference in both gender for the farthest step length. The strongest correlation ration was found in the normalization to limb length and was, consequently, recommended to be used for measuring SEBT. ${ }^{10}$

$\mathrm{Y}$ balance test was developed by Plisky to evaluate the dynamic balance. This tool was specifically developed to overcome several limitations of the traditional SEBT. The testretest interrater reliability of the $\mathrm{Y}$ balance test is good with an acceptable standard error, meaning that this tool is applicable even for the minimally experienced examiner. ${ }^{12}$ Study on Y balance test implementation for dynamic balance evaluation in the specific population of 8-12 year-old children has not been published yet.

Significant improvement in NSEBT scores after the intervention was observed in control and intervention groups in this study (Table 3 ). Long et al. ${ }^{13}$ demonstrated a significant improvement in static and dynamic balance of elderly subjects after 6 weeks of strengthening exercises (3 sessions/week, 2 sets of 10-15 repetitions/session). The exercise procedure applied was tiptoeing in standing position. The previous studies stated that the ankle dorsoflexion exercise in the weight bearing position would significantly increase dynamic balance. $^{14,15}$

The NSEBT score increase in the control group might be caused by the advancement of plantar flexor muscles' strength and postural control, considering that the foot movements were performed in one-leg standing position. These results are similar to those found in Long et al. ${ }^{13}$ study.

Significant improvement of NSEBT scores was found post-intervention in all of the three directions (Table 4). Mean NSEBT scores after intervention in this present study was higher than those of Khatatbeh and Dabayeh's ${ }^{3}$ study that could possibly be caused by differences in foot movement training and measuring tools used.

This study instructed the subjects to move a tea cup between feet and do tip-toeing. Moving a tea cup between feet was considered as a toe curl movement aimed to strengthen the flexor digitorum longus-brevis, lumbricales, and flexor hallucis longus whereas tip-toeing was aimed to strengthen plantar flexor muscles.

Bone structures, ligaments, intrinsic and extrinsic muscles of foot take part in controlling overpronation and maintaining the medial longitudinal arch in weight bearing activities. Extrinsic muscles, including the anteriorposterior tibial muscles and long peroneus muscles, help in stabilizing the midtarsal joint and dynamically support the medial longitudinal arch in stance phase. The intrinsic foot muscles such as hallucis abductor, short digitorum flexor and interosseous muscles contribute in foot stabilization. Among the later, the intrinsic muscles, hallucis abductor muscles are the most important in supporting the medial longitudinal arch and stabilizing and supinating midtarsal joint, especially in resisting pronation ground reaction force during propulsion. ${ }^{16,17}$ Shortening foot, supination-pronation, and tiptoeing to 
Table 3 Comparison of NSEBT Scores

\begin{tabular}{|c|c|c|c|c|c|c|c|c|}
\hline \multirow{3}{*}{$\begin{array}{l}\text { Direction of } \\
\text { Movement }\end{array}$} & \multicolumn{4}{|c|}{ Control Group } & \multicolumn{4}{|c|}{ Intervention Group } \\
\hline & $\begin{array}{c}\text { Mean } \\
(\mathrm{cm})\end{array}$ & $\begin{array}{c}\text { Mean } \\
(\mathrm{cm})\end{array}$ & \multirow[t]{2}{*}{$\mathbf{z}$} & \multirow{2}{*}{$\mathbf{p}$} & \multirow{2}{*}{$\begin{array}{c}\text { Mean } \\
\text { (cm) } \\
\text { Pre }\end{array}$} & \multirow{2}{*}{$\begin{array}{c}\text { Mean } \\
\text { (cm) } \\
\text { Post }\end{array}$} & \multirow{2}{*}{$\mathbf{z}$} & \multirow{2}{*}{$\mathbf{p}$} \\
\hline & Pre & Post & & & & & & \\
\hline \multicolumn{9}{|l|}{ Right limb } \\
\hline NSEBTAN & 54.26 & 57.68 & 3.82 & $0.00^{*}$ & 54.48 & 64.14 & 3.82 & $0.00 *$ \\
\hline NSEBTPM & 62 & 65.79 & 3.82 & $0.00^{*}$ & 60.62 & 69.38 & 3.94 & $0.00^{*}$ \\
\hline NSEBTPL & 57 & 60.42 & 3.72 & $0.00^{*}$ & 53.62 & 63.48 & 3.98 & $0.00^{*}$ \\
\hline \multicolumn{9}{|l|}{ Left limb } \\
\hline NSEBTAN & 54.21 & 58.16 & 3.82 & $0.00^{*}$ & 54.19 & 63.19 & 3.82 & $0.00^{*}$ \\
\hline NSEBTPM & 60.1 & 63 & 3.06 & $0.00^{*}$ & 59.71 & 69.05 & 3.92 & $0.00^{*}$ \\
\hline NSEBTPL & 56.21 & 58.95 & 2.33 & $0.02 *$ & 53.38 & 63 & 4.01 & $0.00^{*}$ \\
\hline
\end{tabular}

Note: *Wilcoxon matched pair test; NSEBTAN = NSEBT Anterior; NSEBTPM = NSEBT Posteromedial; NSEBTPL = NSEBT Posterolateral

strengthen intrinsic and extrinsic muscles of foot were applied in this study.

A study has reported that foot shortening movement is more useful in strengthening the hallucis abductor muscle than the toe curl. ${ }^{17}$ It was also stated that the hallucis abductor muscles work harder when the exercise was conducted in one-leg standing position. This procedure was implemented in this present study.

Khatatbeh and Dabayeh ${ }^{3}$ used the traditional
SEBT method to measure the dynamic balance. The disadvantages of this widely used method is that the examiner has problems in focusing on foot movement while marking the length. Y balance test is adapted in this study to simplify the method in marking foot step reach length and to increase the measurement accuracy. ${ }^{12}$

Significant increase of NSEBT scores in the intervention group was better compared to those of the control group (Table 4). Another study demonstrated a significantly increased

Table 4 NSEBT Scores Difference

\begin{tabular}{|c|c|c|c|c|}
\hline \multirow[t]{2}{*}{ Direction } & \multicolumn{2}{|c|}{ Mean $(\mathrm{cm}) \pm S D$} & \multirow[b]{2}{*}{$\mathrm{Z}$} & \multirow[b]{2}{*}{$\mathrm{p}$} \\
\hline & $\begin{array}{c}\text { Control Group } \\
(\mathrm{n}=19)\end{array}$ & $\begin{array}{l}\text { Intervention } \\
\text { Group }(n=21)\end{array}$ & & \\
\hline \multicolumn{5}{|l|}{ Right Limb } \\
\hline Diff-NSEBTAN & $3.42 \pm 1.50$ & $9.67 \pm 5.06$ & -4.93 & $0.00^{*}$ \\
\hline Diff-NSEBTPM & $3.80 \pm 1.47$ & $8.76 \pm 3.51$ & -4.43 & $0.00 *$ \\
\hline Diff-NSEBTPL & $3.42 \pm 1.35$ & $9.86 \pm 3.98$ & -4.92 & $0.00^{*}$ \\
\hline \multicolumn{5}{|l|}{ Left Limb } \\
\hline Diff-NSEBTAN & $3.95 \pm 1.22$ & $9.00 \pm 4.31$ & -4.96 & $0.00^{*}$ \\
\hline Diff-NSEBTPM & $2.89 \pm 3.02$ & $9.33 \pm 2.59$ & -4.95 & $0.00^{*}$ \\
\hline Diff-NSEBTPL & $2.74 \pm 4.93$ & $9.62 \pm 2.44$ & -5.02 & $0.00 *$ \\
\hline
\end{tabular}

Note: * Mann Whitney U test; SD=standard deviation; Diff: Difference; Diff-NSEBTAN = Diff-NSEBT anterior; DiffNSEBTPM = Diff-NSEBT posteromedial; Diff-NSEBTPL = Diff-NSEBT posterolateral 
strength of plantarflexor muscles in cerebral palsy subjects who were given resistance training for 6 weeks. ${ }^{18}$

A study aimed to determine the immediate effect of short-foot exercise on the dynamic balance of subjects with excessively pronated feet has exhibited improved dynamic balance in subjects trained with foot shortening. ${ }^{19}$ Dynamic balance is improved due to increased proprioceptive stimulation in foot sole to further augment the afferent stimulation in enhancing the stability and also voluntary muscles activity. The study also postulated the roles of increasing foot sole's skin receptor stimulation. Foot shortening causes pressure in ground contact area, hence developing more cutaneous stimulations. Better dynamic balance improvement in intervention group were likely reasoned to the muscle adaptation towards the strengthening exercises, either neural or structural adaptation.

Muscles' structural adaptation due to overload resistance may consist of muscle fibers hypertrophy and hyperplasia. Neural factors influence muscle strength by increased neuron firing recruitment, improved motor unit synchronization and coordination as well as boosted agonist muscles' activity, decreased antagonist muscles' activity, and inhibited muscle protection mechanism (golgi tendon organ)..$^{20}$

This study has several limitations. The relatively short training duration applied in this study is an adapation in order to improve the compliance and also to minimize drop out. Manual Muscle Testing (MMT), which is a widely used tool for assessing strength in children, is examiner-dependent and could not detect small changes in strength so the dynamic balance improvement in this present study could not be concluded as an improvement due to musculoskeletal component or sensory component or a combination of both. There are also possibilities of learning effect and muscle fatigue due to the regularly clock wise order for balance testing.

This study has managed to show different effects of foot muscles strengthening exercises with and without elastic band resistance to dynamic balance of flexible flatfeet children aged 8-12 years. The dynamic balance was improved in both groups though the elastic band resistance group developed a better balance compared to the no resistance group.

\section{References}

1. Benedetti LB, Luciani D. Diagnosis flexible flatfeet in children: a systematic clinical approach. Orthopedics. 2011;34:94-100.

2. Dabholkar A, Shah A, Yardi S. Comparison of dynamic balance between flat feet and normal individuals using star excurtion balance test. Indian J Physiother and Occupational Ther Letter. 2012;6(3):27-31.

3. Khatatbeh M, Dabayeh I. Effectiveness of specialized small motor games for the improvement of dynamic balance in flexible flatfeet. J Med J. 2012;46(4):320-30.

4. Jung DY, Kwon OY. Effect of foot orthoses and shortfoot exercise on the cross-sectional area of the abductor hallucis muscle in subjects with pes planus: a randomized controlled trial. J Back Musculoskelet Rehab. 2011;24(4):25531.

5. Luke A, Kelly SK, Racinais R. Recruitment of plantar intrinsic foot muscles with increasing postural demand. Clin Biomechanics. 2012;27(1):46-51.

6. Resistant band \& tubing instruction manual.

Volume 4. The Hygiene Coorporation. [cited 2014 January 6]. Available from: www. theraband.com.

7. McNee MG, Morrissey MC, Shortland AP. Increases muscle volume after plantarfleksor strength in children with spastic cerebral palsy. Developm Med Child Neurol. 2009;51(6):42935.

8. Chen KC, Yeh CJ, Yang JF. Change in flatfoot of preschool-aged children: a 1-year follow-up study. Eur J Pediatr. 2013;172(2):255-60.

9. Onodera AN, Sacco IC, Morioka EH, Souza PS, de Sá MR, Amadio AC. What is the best method for child longitudinal plantar arch assasment and when does arch maturation occur? Foot (Edinb). 2008;18(3):142-9.

10. Gribble PA, Plisky P. Using the star excursion balance test to asses dynamic postural controldeficits outcomes in lower extremity injury: a systematic literature and review. J Athletic Train. 2012;47(3):339-57.

11. Daniels L, Worthingham C. Muscle Testing. $9^{\text {th }}$ ed. Philadelphia: W.B.Saunders Company; 
2014. p. 203-75.

12. Shaffer LSW, Teyhen LDS, Lorenson CL, Warren RL, Koreerat CM, Strasesk CA, et al. Y-balance test: a reliability study involving multiple raters. Mil Med. 2013;178(11):1264-70.

13. Long L, Jackson K, Laubach L. A home-based exercise program for the foot and ankle to improve balance, muscle performance and flexibility in community dwelling older adults: a pilot study. Int J Phys Med Rehabil. 2013;1(3):1-6.

14. BasnettCR, Hanish MJ, Wheeler TJ, Miriovsky DJ, Danielson EL, Barr JB, et al. Ankle dorsiflexion range of motion influences dynamic balance in individuals with chronic ankle instability. Inter J Sports Phys Ther. 2013;8(2):121-8.

15. Hoch MC, Andreatta RD, Mullineaux DR, English RA, McKeon JM, Mattacola CG, et al. Two-week joint mobilization intervention improves self-reported function, range of motion, and dynamic balance in those with chronic ankle instability. J Orthopaedic Research. 2012;30(11):1798-804.

16. Hagen SL, Bruns D, Gerhardt A, Spichala S, Volkeri O, Hennig EM, et al. Effect of functional pronator and supinator strength training on shank muscle volume and rearfoot in shod running. Footwear Sci. 2009;1(SPPL 1):S64-5.

17. Jung DY, Koh EK, Kwon DY, Cynn H, Lee WH. A comparison in the muscle activity of the abductor hallucis and the medial longitudinal arch angle during toe curl and short foot exercise. Physical Ther Sport. 2011;12(1):305.

18. Jung JW, Her JG, Ko J. Effect of strength training of ankle plantarflexors on selective voluntary motor control, gait parameters, and gross motor function of children with cerebral palsy. J Phys Ther Sci. 2013;25(1):1259-63.

19. Moon D, Kim K, Lee S. Immediate effect of short-foot exercise on dynamic balance of subjects with excessively pronated feet. J Phys Ther Sci. 2014;26(1):117-19.

20. Kraemer WJ, Jason D, Vescovi K. Adaptability of skeletal muscle: response to increased and dereased use. In: Magee DJ, William S. Quillen, editors. Scientific foundation and principles of practice in musculoskeletal rehabilitation. United States: Saunders Elsevier; 2007. p. 7994. 